\title{
CONSCIÊNCIA HISTÓRICA CRÍTICA E ARQUEOLOGIA CLÁSSICA NA ESCOLA: PENSANDO ABORDAGENS A PARTIR DE NOVAS PERSPECTIVAS SOBRE O IMPÉRIO ROMANO
}

\section{CRITICAL HISTORICAL CONSCIOUSNESS AND CLASSICAL ARCHEOLOGY IN SCHOOLS: THINKING APPROACHES ON DIFFERENT PERSPECTIVES ABOUT THE ROMAN EMPIRE}

Felipe Barradas Correia Castro Bastos ${ }^{1}$ Jéssica Louise Rocha Neiva de Lima

Resumo: Proporemos, neste artigo, pensar de que maneira a interdisciplinaridade entre Arqueologia e História pode propiciar conhecimentos que reflitam sobre a pluralidade do passado romano. A partir do estabelecimento de diálogos entre a academia e a escola, o objetivo deste artigo é defender o potencial desse saber arqueológico para que os alunos possam compreender a diversidade de sujeitos, relações e culturas de maneira mais temporalizada e multifacetada, tendo em vista a relação entre o passado e presente. Pretendemos refletir sobre a possibilidade de inserir os estudos recentes sobre a cultura material do início do princi-

\footnotetext{
${ }^{1}$ Aluno do $5^{\circ}$ período de História na Universidade Federal do Paraná. E-mail: felipebccbastos@hotmail.com

${ }^{2}$ Aluna do $5^{\circ}$ período de História Universidade Federal do Paraná. E-mail: jessica.neivadelima@gmail.com
}

\section{Agradecimentos:}

É importante apresentarmos que a motivação deste decorre de uma disciplina de graduação, ministrada pela Prof ${ }^{a}$ Dr $^{a}$. Renata Senna Garraffoni, cuja proposta consistia em suscitar questionamentos sobre o distanciamento da Academia e das escolas, propondo aos alunos romperem estas barreiras por meio da Arqueologia. Desta maneira, gostaríamos de agradecer à Prof ${ }^{a}$ Garraffoni pelas discussões em sala de aula, as quais nos permitiram perceber a importância do papel do historiador para o desenvolvimento de uma História crítica em sala de aula. 
pado romano, no século I d.C., nas salas de aula, aliando o referencial teórico de Jörn Rüsen referente à "consciência histórica crítica" à proposta da Arqueologia Pública de estabelecer relações mais profícuas e menos hierarquizadas entre o conhecimento acadêmico e as escolas.

Palavras-chave: Arqueologia, Historiografia, Império Romano, Consciência Histórica Crítica, Ensino de História.

Abstract: The aim of this paper is to discuss how Archaeology and History may provide knowledge for a more pluralist approach of the Roman Empire. We also intend to discuss the relationship between Academy and schools, and how Archaeology can help to understand the diversity of subjects, relations and cultures, considering the relations between past and present. To do so we suggest the importance to discuss material culture among students considering Jörn Rüsen's theoretical framework on "critical historical consciousness" with Public Archaeology's proposal of establishing more fruitful and less hierarchized relations between academic knowledge and schools.

Keywords: Archaeology, Roman Empire, diversity, Jörn Rüsen, critical historical consciousness.

\section{Introdução}

Quando nos propusemos a escrever este artigo sobre como a Arqueologia pode contribuir com a construção de um ensino de História crítico, inevitavelmente nos questionamos "qual o propósito da História?". Afinal, ao propormos a escrita de um artigo destinado a professores de História atuantes na docência, incidimos na questão da ação dos professores e o propósito de formação de alunos nesta disciplina em sala de aula. Entendemos que os historiadores docentes, na prática da exposição do conteúdo, não visam apenas aludir a fatos e grandes personalidades sobre o passado, mas relacionar estes com o presente do aluno e com sua vivência no mundo. 
A discussão a seguir tem por objetivo refletir sobre a proposta da Arqueologia Pública, de interação entre a produção científica acadêmica e a sociedade, para pensar a abordagem da Arqueologia Clássica em sala de aula. Na sequência, argumentaremos que as problematizações oriundas de debates arqueológicos podem ser aplicadas proficuamente pelos docentes em História, visando o desenvolvimento de uma "consciência histórica" nos alunos, e proporcionando-lhes uma maior sensibilidade com o passado e suas profundas relações com o presente. Para tanto, articularemos aos objetivos da Arqueologia pública o referencial conceitual proposto pelo teórico da história Jörn Rüsen, cuja teoria de filosofia histórica erige uma reflexão construtiva sobre didática, ensino e objetivos da História nas salas de aula. Em seguida, faremos uma breve revisão bibliográfica de estudos arqueológicos cujas propostas teóricas vão ao encontro dos objetivos desse artigo: demonstrar o grande potencial da Arqueologia em desenvolver um estudo da História de maneira crítica, de modo a proporcionar aos alunos uma visão multifacetada do passado e desenvolver, com isso, maior sensibilidade com o conhecimento histórico.

O artigo se dividirá em três partes: a primeira consiste em desenvolver o diálogo entre Arqueologia pública nas escolas e a possibilidade um ensino de História que proporcione ao aluno "consciência histórica", por meio do levantamento dos principais conceitos teóricos de Rüsen. A segunda e a terceira parte visam apresentar uma breve revisão bibliográfica de arqueólogos e historiadores, tendo como recorte temático o Império Romano, propondo abordar perspectivas teórico-analíticas que 
propiciam a construção de visões críticas do passado clássico, partindo da desconstrução e problematização de modelos teóricos que se propõem explicar o Império Romano de maneira monolítica, normativa e imperialista. O levantamento bibliográfico se dará em dois momentos: no primeiro, serão abordados aspectos referentes à economia, expansão militar e contatos culturais no Império Romano. No segundo, tratar-se-á de temas relativos a gênero e práticas sexuais no século I d.C, em Roma. Elencaremos, a seguir, referenciais teóricos compatíveis com nossa proposta de vincular a academia e a escola para tornar alunos em cidadãos críticos, refletindo sobre o lugar da Arqueologia Clássica nesse processo.

\section{Arqueologia na escola e o desenvolvimento de uma História crítica}

Para os objetivos propostos neste artigo, é fundamental questionar como a disciplina de História é tratada em sala de aula. Conforme expõe Medeiros (2006), é possível observar, em muitos livros didáticos de História, que a exposição do conhecimento histórico ainda está fortemente vinculada a uma perspectiva estritamente factual, pautada somente na política e economia das sociedades, voltada à existência de uma verdade histórica. Este tipo de abordagem se articula em uma narrativa constituída por sequências de fatos em versões homogêneas da História. Um primeiro problema apresenta diante dessa reflexão: como pode o professor de História discorrer sobre a diversidade no passado ao invés de narrar sequências factuais de causalidades e consequências? 
Medeiros (2006) realizou uma discussão muito frutífera acerca da aplicabilidade dos conceitos de Jörn Rüsen nos livros didáticos. $\mathrm{O}$ ponto de maior relevância para nossa análise são os questionamentos que o autor propõe para o desenvolvimento de um livro didático que seja capaz de auxiliar tanto ao professor, quanto ao aluno, no desenvolvimento de uma consciência histórica crítica. Isto é, pensar a diversidade a partir do presente, tendo um vista uma temporalização entre o passado e perspectivas para o futuro. O objetivo da consciência histórica crítica é habilitar o aluno para o entendimento das funções do conhecimento histórico, partindo-se delas para gerar, conforme propõe Rüsen, um sentido histórico - entendido como a compreensão das experiências de mudanças temporais para se entender como indivíduo e como indivíduo em uma cultura.

Schmidt e Garcia (2005) também proporcionam uma análise acerca dos conceitos de Rüsen. Segundo as autoras, um dos princípios fundamentais para a didática da História rüseniana se refere às "finalidades e objetivos do ensino de história e envolve questões como 'para que serve ensinar a história?', 'por que trabalhar história na escola?' e 'que significado tem a história para alunos e professores?"' (SCHMIDT e GARCIA, 2005, p. 299). Para responder esses questionamentos, as autoras postulam que os conteúdos da disciplina de História sejam ensinados sob perspectivas que objetivam uma sensibilização entre o aluno e o conteúdo, isto é, atentem para as possibilidades de se pensar o presente e o passado nos limites de uma relação temporalizada. 
Dessa forma, reitera-se a importância dos referenciais teóricos de Rüsen sobre a "consciência histórica", conceito constituído por concepções nas quais o curso do tempo adquire um senso crítico especial por entender o passado como experiência inerente à mudança temporal, orientado para as mudanças vindouras no futuro a partir do presente. Isto é, a consciência histórica tem como função específica a compreensão da realidade passada tendo em vista o presente, em uma relação de indissociabilidade. Para as autoras (SCHMIDT e GARCIA, 2005), Rüsen articula a relação entre identidade e ação - o "ser" e "dever" dos indivíduos - na consciência histórica para cumprir uma função prática: "dar identidade aos sujeitos e fornecer à realidade em que eles vivem uma dimensão temporal, uma orientação que pode guiar a ação, intencionalmente, por meio da mediação da memória histórica" (SCHMIDT e GARCIA, 2005: 301).

É por meio deste processo subjetivo de compreensão do sentido da experiência humana no tempo que o aluno será capaz de desenvolver para si uma consciência histórica. Esta consciência, por sua vez, permitirá ao indivíduo entender-se como um ser temporal, integrando o conhecimento sobre o passado ao seu presente e possibilitando perspectivas, mesmo que utópicas, sobre o futuro.

Eis então o propósito teórico axial deste trabalho, segundo as reflexões epistemológicas de Rüsen (2010): a disciplina histórica deve ser ensinada, em sala de aula, de maneira a possibilitar que o aluno entenda como é construído o conhecimento historiográfico, permitindo que se estude a História não de maneira factual, alicerçada na busca por uma 
suposta verdade histórica e um passado unilateral, mas de maneira múltipla, entendendo-a como uma narrativa que é construída por metodologias e modelos teóricos que englobam a própria subjetividade do historiador. É essa consciência da construção do conhecimento historiográfico que estimulará o aluno a caminhar no sentido de desenvolver a consciência histórica, permitindo integrar o desenvolvimento historiográfico com o contexto contemporâneo no qual os historiadores se inserem, sensibilizando o aluno temporalmente, de modo a tornar perceptível o vínculo entre a temporalidade e a construção do indivíduo. Nesse sentido também se envereda a argumentação de Schmidt e Garcia (2005), segundo as quais os conceitos rüsenianos indicam que:

a construção da consciência histórica exige conteúdos que permitam o desenvolvimento de uma argumentação histórica crítica, de uma contranarrativa, na medida em que tais contextos buscam a mobilização, não de todo o passado, mas de experiências específicas do passado relacionadas a sua própria experiência. A partir do seu presente e de sua experiência, alunos e professores se apropriam da história como uma ferramenta com a qual podem romper, destruir e decifrar a linearidade de determinadas narrativas históricas, fazendo com que elas percam o seu poder como fonte de orientação para o presente (SCHMIDT e GARCIA, 2005, pp. 303 - 304).

O potencial da "consciência histórica" para a formação crítica dos alunos, tanto enquanto indivíduo e coletividade (SCHMIDT e GARCIA, 2005) se explicita a partir de procedimentos didáticos que evidenciem, aos alunos, que as narrativas construídas sobre o passado não são apenas dadas no âmbito da continuidade, mas também no âmbito da mudança, 
logo, da diferença. No limite, essa consciência permite o desenvolvimento de uma História mais plural ao admitir uma série de posicionamentos que, a partir do reconhecimento da diversidade como legítima no passado e no presente, nos quadros de uma relação temporalizada, enquanto respeita os espaços para diferenças sociais, históricas e culturais, reconhecendo sua legitimidade no decorrer da História. Esta necessidade de desenvolver uma História pluriperspectivista em sala de aula, como aponta Medeiros (2006), é o que possibilita ao aluno lançar um olhar crítico sobre a História, posicionando-se como indivíduo pensante diante do conhecimento que recebe, não sendo um mero receptor inerte, incapaz de atrelar o conhecimento científico a sua visão de mundo.

Explorados estes conceitos de Rüsen, devemos agora conectá-los com a intenção de trabalhar a Arqueologia como uma possibilidade de estudarmos o passado, neste caso Clássico, de modo a permitir uma maior sensibilidade do aluno com a História. $\mathrm{O}$ vínculo entre o saber acadêmico arqueológico e a sala de aula, buscando um passado plural, será articulado a partir do referencial teórico de Jörn Rüsen acerca da "consciência histórica crítica" e da proposta da Arqueologia Pública, defensora da aproximação entre a academia e a sociedade.

Problematizar o próprio papel da Arqueologia na produção de conhecimento sobre o passado é fundamental para vislumbrar seu potencial de construir, ratificar ou se contrapor a determinadas visões sobre o passado. De acordo com Funari e Garraffoni (2006), a Arqueologia vem se emancipando do seu papel tradicional subalterno à 
História, isto é, de prover, por meio dos estudos da cultura material, ilustrações e confirmações aos textos escritos, notadamente no contexto da Arqueologia Clássica. A partir da defesa de seu status independente enquanto campo científico autônomo, a disciplina adquire grande relevância em seu potencial de propor novas visões críticas sobre o passado em geral, propondo a desconstrução de modelos interpretativos normativos e homogeneizantes em prol de análises que enfatizem a diversidade e heterogeneidade. Os estudos de caso propostos pela bibliografia levantada exemplificarão essa dinâmica.

A Arqueologia Pública vai ao encontro das reflexões acima, pois por meio de sua proposta de desenvolver um diálogo entre o conhecimento arqueológico e o conhecimento tradicional da sociedade, sem hierarquizá-los nem colocá-los em relações unilaterais de poder, entendemos a necessidade de levar a Arqueologia à sala de aula.

Assim, a proposta da Arqueologia Pública de aproximação entre a academia e a escola reflete o potencial do estudo da cultura material para propiciar diferentes visões acerca do passado e, no limite, incidir sobre a formação de consciências históricas críticas nos alunos. A Arqueologia Pública tem a preocupação de "tornar as comunidades em agentes e colaboradoras ativas da pesquisa arqueológica" (CARVALHO e MENEZES, 2013: 11),desenvolver nos alunos uma maior aproximação da vivência de mundo destes com o conhecimento acadêmico, de forma que o estudo de História por meio de um passado múltiplo incentive o aluno a se identificar com este conhecimento.

Partindo das discussões do Laboratório de Arqueologia Pública 
da UNICAMP ${ }^{3}$, bem como pelas considerações de Pedro Paulo Funari (2001), optamos por fazer um levantamento bibliográfico de trabalhos que analisem vestígios arqueológicos. Isto se deve não apenas pelo fato da cultura material ser pouco explorada nas salas de aula, mas também por ela proporcionar, por meio de abordagens teóricas pósprocessualistas, uma visão do passado multifacetada e mais próxima ao cotidiano do aluno. A cultura material é capaz de proporcionar ao aluno informações que, muitas vezes, confrontem as fontes escritas, ou explore temáticas não abarcadas por elas (FUNARI, 2001). É importante observarmos que, quando se estuda a Roma Antiga, os documentos escritos na maioria das vezes se vinculam a um estrato muito específico da sociedade, sendo por meio dos estudos da cultura material que se proporciona novas visões da sociedade Clássica por uma multiplicidade de caminhos, desde o estudo dos grafites, de ânforas e até objetos utilizados no cotidiano das populações antigas.

Foi a partir das inovações teórico-metodológicas da Arqueologia que muitas visões unilaterais sobre o passado romano foram questionadas. Este passado era recorrentemente concebido pela historiografia do século XIX a meados do século XX, por perspectivas androcêntricas e imperialistas, que levaram à utilização de conceitos como "romanização", bem como ao desenvolvimento de modelos teóricos sobre as práticas sexuais romanas pautados em uma visão política e masculina da sociedade. Discutindo esta visão

\footnotetext{
${ }^{3}$ Para mais informações sobre o vínculo entre o LAP e as escolas, ver Carvalho e Menezes (2013).
} 
homogeneizante por meio da arqueologia, trataremos a seguir de trabalhos acadêmicos que proporcionaram novas visões sobre o mundo acadêmico, buscando mostrar a pluralidade de sujeitos históricos e possibilitando uma maior sensibilização com o passado romano. A partir disso, põem-se em evidência como os estudos da cultura material possibilitam novas maneiras de interpretar esse passado e, portanto, constituir outras consciências históricas voltadas ao senso crítico a partir da Arqueologia Clássica.

\section{Arqueologia Clássica romana e consciência histórica:}

1. Estudos de economia, expansão imperial e contatos culturais

O primeiro eixo de argumentação busca elucidar determinados aspectos sobre a economia, expansão militar e contatos culturais no alvorecer do Império Romano durante o século I d.C. Tendo em vista os estudos arqueológicos recentes e seus desdobramentos sobre a historiografia, no que tange esses três temas, propõe-se articular referências materiais e pressupostos teórico metodológicos que tornem possíveis a formulação de novas perspectivas sobre o passado e, no limite, potencializar a construção de consciências históricas críticas no sentido rüseniano.

Contudo, antes de partirmos para a análise das contribuições que as pesquisas arqueológicas trouxeram à compreensão do Império Romano, é de grande importância aludir ao processo de desenvolvimento histórico da organização da Arqueologia Clássica enquanto disciplina aca- 
dêmica, no século XIX. Renata Senna Garraffoni, Pedro Paulo Funari e Renato Pinto (2010) se debruçaram sobre essa questão e produziram uma série de reflexões que nos possibilita compreender a trajetória da disciplina de Arqueologia, e como o conhecimento produzido em seu seio serviu para sustentar diversos posicionamentos políticos contemporâneos aos arqueólogos - refutando, portanto, a noção de que o aparente afastamento temporal entre o período Clássico e os séculos XIX e XX conferiria ao arqueólogo neutralidade e passividade diante do passado.

Estes autores sustentam que, sob o manto imaculado das disciplinas que compunham os "estudos clássicos" oitocentistas - cujos estudiosos atribuíam a si mesmos e as suas interpretações sobre o passado uma neutralidade e veracidade - a Arqueologia Clássica se desenvolveu em academias europeias arraigadas de prerrogativas nacionalistas, padrões normativos, concepções neocoloniais, imperialistas e evolucionistas. As várias discussões epistemológicas realizadas no cerne das Ciências Humanas e, por consequência, da Arqueologia suscitaram, desde finais do século $\mathrm{XX}$ aos nossos dias, numerosas novas maneiras de se analisar e compreender o passado clássico ao fazer uso de novas abordagens teórico-metodológicas. Esses levantamentos de ordem teórica são de grande serventia para uma visão mais abrangente sobre o conjunto das ferramentas e ideologias que confeccionam os diferentes modelos interpretativos que compõem a disciplina e, a partir desse entendimento, propiciar novas consciências históricas críticas que se embasem em uma História menos excludente, homogeneizante e progressista. 
Retomando a discussão sobre a independência da Arqueologia em relação à História enquanto campo científico autônomo, e de suas contribuições aos estudos sobre a Roma Antiga, Funari e Garraffoni exemplificam a importância de análises da cultura material que não busquem apenas ilustrar os escritos romanos. Os autores indicam que, embora os textos do geógrafo romano Estrabão contenham relatos significativos sobre a economia romana, estes se inseriam em um contexto específico laudatório à expansão imperial de Roma enquanto ressaltava os hábitos bárbaros dos povos conquistados (FUNARI e GARRAFFONI, 2006: $55)$.

Ao refletirmos, então, como enfocar a economia romana pelas perspectivas reveladas por meio das análises arqueológicas, o que pode ser extraído da cultura material? A economia romana, similarmente a outras sociedades do mundo antigo, dependia em grande medida da produção agrícola. Segundo os referidos autores, as uillae romanas, locais onde se produziam diversos produtos agrícolas e se fabricavam os recipientes para seu envase, comércio e transporte, podem fornecer importantes dados sobre a produção de azeite, o cultivo de vinícolas, cereais e das ânforas que transportariam esses produtos pelo Império (FUNARI e GARRAFFONI, 2006).

De fato, escavações realizadas em uillae na Hispania romana, atual Espanha, revelaram uma vasta quantidade de ânforas utilizadas para transportar azeite. Estudos epigráficos e morfológicos dessa cultura material, catalogada sob a nomenclatura de ânforas Dressel-20, permitiu aos arqueólogos identificar e encontrar ânforas produzidas nesta região 
em localidades longínquas, como a Britannia, militarizada região fronteiriça imperial correspondente à atual Inglaterra. Jose Remesal ${ }^{4}$ é um importante estudioso dessas ânforas transportadoras de azeite produzidas na Hispania. Este autor constata a sua presença massiva em um grande número de acampamentos militares romanos em locais muito afastados do Mediterrâneo, isto é, em locais onde o azeite de oliva não figurava entre os hábitos alimentares das populações (REMESAL, 2004).

De volta à argumentação de Funari e Garraffoni (FUNARI e GARRAFFONI, 2006), as implicações dessa evidência arqueológica encontrada em grandes quantidades nos acampamentos militares romanos na Britannia sugere que o azeite de oliva produzido na Hispania estava inserido em uma ampla rede de abastecimento às legiões romanas. A análise crítica proposta por estes autores se direciona ao consumo do azeite nessas regiões limítrofes do Império, um produto chegado com a conquista dessas regiões e que entrou em contato com povos que não o produziam nem o utilizavam tradicionalmente, como os bretões nativos da Britannia. Assim, a difusão e consumo do azeite entre os soldados e os nativos nessa região era uma prova de sua adesão ao Império Romano (FUNARI e GARRAFFONI, 2006:60).

A análise empreendida por Funari e Garraffoni parte justamente de reflexões críticas acerca do papel da Arqueologia e a formação de

\footnotetext{
${ }^{4}$ José Remesal Rodríguez é diretor do CEIPAC - Centro para el Estudio de la Interdependencia Provincial en la Antigüedad Clásica da Universidade de Barcelona, cujo site contém várias publicações e materiais disponíveis online. Para mais informações: http://ceipac.gh.ub.es/. Acesso em 22/05/14.
} 
conhecimento histórico para, ao encontro da proposta de Remesal (2004), produzir um maior entendimento sobre a economia romana, pensada em suas íntimas correlações, àquele contexto histórico, com o abastecimento das legiões romanas nas fronteiras do Império. Ao proceder dessa maneira, buscam evidenciar o dinamismo da economia romana em seus vínculos ao exército e administração imperiais de modo a descobrir relações muito mais complexas entre romanos e nativos nas fronteiras militarizadas do Império. O potencial dessa análise para a formação de uma consciência histórica crítica se encontra, portanto, precisamente na complexidade e diversidade de relações entre romanos e nativos, pensadas sob a perspectiva da economia e do abastecimento militar de Roma.

Outras perspectivas de análise foram produzidas a partir dos vestígios romanos encontrados na Britannia, decorrentes das conquistas das legiões romanas no século I d.C. Por mais evidente que possa ser o sucesso das campanhas militares empreendidas durante o principado, vários estudiosos que as estudaram durante os séculos XIX e XX se esforçaram para construir modelos interpretativos que, ao incidirem sobre a expansão imperial romana, produziram uma série de conceitos muito condizentes com ideologias vigentes no próprio imperialismo desses dois séculos.

Richard Hingley (2010) realiza uma ampla discussão acerca da atividade desses estudiosos na construção de um "legado" romano passado ao Império Britânico. Hingley aponta que a criação do conceito de "romanização", tal como um processo de mudança progressiva forço- 
samente vinculada a questões militares e culturais a partir da presença dominadora dos romanos nos limites do Império sobre os povos dominados, possui vários paralelos com os conceitos muito caros ao imperialismo contemporâneo como "progresso" e "desenvolvimento" (Hingley 2010: 33). Em outras palavras, "romanização" designa a aculturação de um povo nativo em detrimento da cultura romana. Nessa lógica, a cultura material existente em sítios britânicos, conforme aponta Hingley, foi utilizada como demonstração da existência da "romanização" dos povos nativos da Britannia (Hingley, 2010: 51).

A Arqueologia Clássica, pelas perspectivas referidas acima, pode atentar à diversidade no passado ao vislumbrar a economia romana a partir de redes de abastecimento que, ao serem cruciais na expansão do exército, propiciam contatos diversos entre os povos nativos e os romanos após a conquista de novos territórios - o caso da distribuição de azeite produzido na Hispania na Britannia por meio das ânforas Dressel-20 e as complexas relações entre sua difusão e consumo entre as legiões e os povos nativos desta região. A abordagem de Funari e Garraffoni vai ao encontro das críticas de Hingley acerca do conceito de "romanização", na medida em que o consumo de azeite na Britannia foi entendido como uma evidência da adesão dessa região ao Império, isto é, na "romanização" dos povos por meio do consumo do azeite enquanto evidência da presença de hábitos alimentares romanos em regiões conquistadas. Em suas palavras, "as sociedades britânicas não eram homogêneas, nem era a romana, logo ir de nativo a romano é um conceito igualmente ilusório por assumir homogeneidade onde existe 
heterogeneidade, tanto nas comunidades bretãs como na sociedade romana" (FUNARI e GARRAFONI, 2006: 57-58).

Em suma, esses trabalhos questionam categorias ideais e estanques de análise ao apontar funções econômicas e implicações culturais da expansão das legiões romanas. Tal procedimento permite, por sua vez, um entendimento mais plural do passado, ao tornar mais complexas as relações políticas e culturais entre romanos e nativos. Nos realudimos à Rüsen: evidencia-se a utilidade da cultura material na formação de consciências históricas críticas ao apontar para um passado mais plural e, além disso, em aproximar o aluno das discussões epistemológicas do conhecimento histórico ao contextualizar criticamente a constituição da Arqueologia Clássica como disciplina acadêmica. A seguir, buscaremos tratar das complexidades culturais que podem ser apreendidas por meio dos estudos da cultura material de outra perspectiva.

\section{Estudos de gênero, sexualidade e religiosidade}

A proposta de trabalhar com recentes discussões Arqueológicas que abrangem o assunto de gênero, práticas sexuais e religiosidade se fez necessária por serem questões muito presentes na vida dos estudantes.

Aproximando o olhar aos conceitos da Arqueologia Pública, conforme explicitamos anteriormente, o professor pode articular o conhecimento prévio dos alunos com os conhecimentos acadêmicos, 
partindo, desta forma, da proposta de uma Arqueologia Democrática ${ }^{5}$, a qual não hierarquiza o conhecimento acadêmico em detrimento do conhecimento tradicional, o aluno pode se sentir sensibilizado e identificar-se com este passado ou perceber as diferenças do passado ao seu tempo presente, desenvolvendo a capacidade de articular-se temporalmente, dialogando o conhecimento historiográfico com a sua vivência no mundo.

Conforme tratamos no caso dos modelos econômicos, políticos e de contatos culturais do Império Romano, a argumentação desta terceira parte será realizada a partir de uma breve revisão bibliográfica de trabalhos voltados ao estudo da cultura material de Pompeia, os quais têm como proposta a desconstrução de grandes modelos teóricos homogeneizantes, tendo em vista o nosso objetivo de pensar os potenciais da Arqueologia para contribuir um ensino de História crítico.

A busca por uma História heterogênea se vincula fortemente ao estudo de Lourdes Feitosa (2008) a qual propõe, por meio da cultura material, um modelo teórico sobre o amor e práticas sexuais romanas, que questiona aspectos mais tradicionais da historiografia.

A crítica da autora se pauta justamente na rigidez estabelecida à sexualidade romana ao desenvolver uma ideia de práticas sexuais pautadas apenas nas concepções aristocráticas. Feitosa, utilizando como documento os grafites parietais ${ }^{6}$, explora uma nova perspectiva a

\footnotetext{
${ }^{5}$ Conceito este entendido a partir da Arqueologia Pública, a qual busca a interação entre conhecimento acadêmico e sociedade.

${ }^{6}$ Escritos realizados em superfícies duras, normalmente no reboco de paredes, através de um objeto pontiagudo denominado stilus.
} 
respeito das afetividades e do amor vinculados ao cotidiano da sociedade romana. Analisando a escrita dos grafites, a autora depara-se com declarações de amor e registro de súplicas amorosas de homens pedindo "o amor da mulher estimada" (FEITOSA, 2008:134). Em um dos grafites estudados pela autora:

Amethuthu nec sine sua Velentina (CIL, IV, 48558) (Ametusto não vive sem sua Valentina) ${ }^{7}$

A análise da cultura material proposta por Feitosa nos possibilita desconstruir modelos teóricos que tratam sobre práticas sexuais e afetividade romanas unicamente de um ponto de vista político, construindo a imagem do romano como o homem viril e dominador, permitindo desta forma novas interpretações do passado de maneira mais plural, mostrando o homem romano também como alguém que pronuncia declarações amorosas, faz súplicas e escreve mensagens de saudades.

Tratando das práticas sexuais, outra discussão realizada por Lourdes Feitosa, há as interpretações dos grafites que possuem a palavra futuere. Este verbo é utilizado, segundo a autora, na voz ativa tanto para homens como para mulheres nos grafites analisados, propondo, deste modo, uma visão ativa nas praticas sexuais para ambos os sexos, não apenas aos homens. Outra reflexão sobre a palavra futuere é de sua capacidade apotropáica, não vinculada apenas ao ato sexual, mas

\footnotetext{
${ }^{7}$ Tradução realizada por Feitosa (2008, p.133).
} 
também à simbologia cosmogônica da sociedade.

Estas novas abordagens teóricas permitem a construção de novas visões da sociedade romana, não esquecendo um passado diversificado, abrindo para novas possibilidades de vivencias humanas, sem normatizar suas atitudes nos campos identitário sexual e de relação de gênero (PINTO, 2011, p.24). É por meio desta proposta de ressaltar a diversidade do passado, entendendo a construção historiográfica como uma narrativa, que abrimos a possibilidade ao aluno, pelas abordagens da Arqueologia, se relacionar com diferentes experiências temporais da vivência humana. Dessa maneira, o aluno pode criticar e desconstruir seus próprios preconceitos.

A respeito da religiosidade, refletiremos sobre o artigo de Renata Garraffoni (2012), no qual se desatrela a religiosidade romana aos vínculos exclusivamente institucional e político. A autora faz uma critica aos modelos teóricos que se voltam apenas a uma pequena elite romana, composta pelas hierarquias sacerdotais e institucionais, e silenciam a religiosidade vinculada ao cotidiano desta sociedade.

Garraffoni (2012) analisa inscrições parietais, no sítio arqueológico de Pompeia, referentes à deusa Vênus, no período do início do principado. Nessas inscrições, é possível observar diferentes formas de representações e relacionamentos religiosos com Vênus, e a reflexão da autora se orienta no sentido de compreender as relações entre percepções amorosas e a religião no contexto romano, propondo o vínculo desta divindade com êxitos e fracassos amorosos. A seguinte passagem exemplifica essa percepção: 
Quisqui amat ueniat : veneris uolo frangere costas. Fustibus et lumbis debilitare deae: si pot(is) illa mihi pertundere pectus, quit ego non passim caput illae frangere fuste? (CIL, IV, 1824) (Que aqui venha quem ama: quero quebrar as costas de Vênus a pauladas e deixar seu lombo machucado. Se ela pode trespassar meu terno coração, porque não poderia eu rachar sua cabeça com um pau?) (GARRAFFONI, 2012, p.213). ${ }^{8}$

Garraffoni interpreta esta relação violenta do indivíduo com a deusa, para expressar uma desilusão amorosa, demonstrando o vínculo intimo que possui entre o indivíduo e Vênus. Vênus, a deusa capaz de intervir nos relacionamentos, afetava de modo ativo àquela sociedade, capaz, segundo Garraffoni, de ser materializada, pela escrita, pelas angústias e percepções da vida amorosa dos indivíduos. Desta forma, a autora nos proporciona um olhar sobre a religião que não se atrela aos grandes modelos teóricos que a vinculam à política, mas sim aos problemas vividos pelos indivíduos, neste caso, no âmbito amoroso.

Além desta desconstrução de uma religiosidade romana vinculada necessariamente à política, permitindo um olhar às praticas sociais, é interessante abordarmos o trabalho realizado por Garraffoni e Sanfelice (2011) pelo qual as autoras abordam as relações entre religiosidade, praticas sexuais e fertilidade.

Por meio da análise das pinturas parietais relacionadas às praticas sexuais romanas, as autoras defendem que as praticas sexuais para os romanos não faziam parte de uma esfera compartimentada da vida,

\footnotetext{
${ }^{8}$ Optamos pela tradução em português feita por Feitosa.
} 
estando estas vinculadas intrinsecamente à cosmogonia religiosa desta sociedade, uma exemplificação é a interpretação dada por Garraffoni e Sanfelice a respeito da imagem do deus Príapo na entrada de uma casa romana de elite, a qual era utilizada como símbolo de proteção.

Por meio desta breve apresentação, devemos novamente apontar a possibilidade de utilizar a cultura material para construir um passado multifacetado, pleno de diferentes experiências históricas. A experiência da religiosidade, atrelada à sexualidade romana, permite um novo olhar histórico ao aluno, diferenciado da experiência de sua sociedade cristã, na qual a religião e a sexualidade não se vinculam.

\section{Considerações finais}

Por meio deste artigo tivemos a intenção de expor como a Arqueologia é capaz de proporcionar o estudo de um passado mais multifacetado e próximo à vivência dos alunos. Se voltarmos ao questionamento realizado na introdução do artigo "qual o propósito da História", segundo esta abordagem, seu propósito não é apresentar uma sequência homogênea de fatos e causalidades aos alunos, mas sim o desenvolvimento de uma consciência histórica. Isto é, propiciar uma didática narrativa de modo que estes alunos sejam capazes de se compreenderem temporalmente.

Tendo em vista que o passado pode ser entendido tanto como meio de identificação como de estranhamento, percebendo suas similitudes e diferenças, a consciência histórica de Rüsen propõe pensamentos críticos na medida em que atentam às heterogeneidades do 
passado. Conforme buscamos demonstrar, os últimos estudos sobre a cultura material da Roma Antiga podem ser de grande utilidade ao desvendar um passado constituído pela pluralidade e complexidade em diferentes temáticas.

A busca por novos sujeitos históricos e a apresentação de várias possibilidades de visões sobre o passado, propicia ao aluno, a experiência de se deparar com diferenciadas vivências históricas e visões de mundo. Desta maneira, a Arqueologia torna-se um instrumento para a construção de uma História crítica, permitindo ao aluno se deparar com seus preconceitos e desconstruí-los com base em seu conhecimento histórico.

\section{Referências Bibliográficas}

CARVALHO, Aline; MENEZES, Victor. Práticas em Arqueologia Pública: considerações acerca do projeto "LAP com as Escolas". In: ANAIS I Semana de Arqueologia “Arqueologia e Porder".

FEITOSA, Lourdes. Gênero e Sexualidade no Mundo Romano: a Antiguidade em nossos dias. In: História Questões e Debates; Editora: UFPR , n.48/49, 2008, p.119-135.

FEITOSA, Lourdes C . Amor e sexualidade: o masculino e o feminino em grafites de Pompéia. São Paulo: Annablume; FAPESP, 2005.

FUNARI, Pedro Paulo. A Arqueologia Histórica em uma Perspectiva Mundial. In: Revista de História Regional, v.6, 2001, p.35-41.

FUNARI, Pedro Paulo. GRILLO, Geraldo. A diversidade no mundo romano: considerações sobre as contribuições da Arqueologia. In: Caminhos da História. Editora Unimontes, 2010, p.11-22.

FUNARI, Pedro Paulo. GARRAFFONI, Renata Senna. A Economia 
Romana no Início do Principado. In: Repensando o Império Romano: perspectiva socioeconômica, política e cultural. Rio de Janeiro: Maud; Vitoria, ES: EDUFES, 2006, p. 53-64.

FUNARI, Pedro Paulo; GARRAFFONI, Renata Senna; PINTO, Renato. O Estudo da Antiguidade no Brasil: As contribuições das discussões teóricas recentes. In: HINGLEY, Richard. O Imperialismo Romano: Novas perspectivas a partir da Bretanha. Editora Annablume, São Paulo, 2010.

GARRAFFONI, Renata. La religión y el cotidiano romano: el ejemplo de las paredes de Pompeya. Gil, Pablo (org.). In: La memoria en la piedra: estudios sobre grafitos históricos. Navarra, 2012, p.221-230.

GARRAFFONI, Renata. SANFELICE, Pérola. A religiosidade em Pompeia: memória, sentimentos e diversidade. In: Mineme-Revista de humanidades, 12(30), 2011 (jul. dez), p.204-226.

HINGLEY, Richard. O Imperialismo Romano: Novas perspectivas a partir da Bretanha. Editora Annablume, São Paulo, 2010.

MEDEIROS, Daniel. Manuais didáticos e formação da consciência histórica. In: Educar, Curitiba, Especial. Editora: UFPR, 2006, p. 73-92.

PINTO, Renato. Duas rainhas, um príncipe e um eunuco: gênero, sexualidade e as ideologias do masculino e do feminino nos estudos sobre a Bretanha Romana. Campinas: UNICAMP (tese de doutoramento em História), 2011.

REMESAL, Jose. El Abastecimiento Militar Durante el Alto Imperio Romano. Un modo de entender la economía antigua. In: Boletim do $C P A$, Revista de Estudos Filosóficos e Históricos da Antiguidade. Campinas, UNICAMP, 2004, p. 163 - 182. 